\title{
GILBERTO FREYRE E A ARTICULAÇÃO DOS NÍVEIS MICRO E MACRO NA SOCIOLOGIA*
}

\section{Jorge Ventura de Morais José Luiz Ratton Jr.}

\section{Introdução}

Gilberto Freyre é um dos intérpretes do Brasil mais analisados na ciência social nacional. É também um dos autores brasileiros mais lidos e debatidos no exterior. Sobre sua obra, no Brasil,

* A idéia deste artigo surgiu primeiro em um grupo de leitura sobre a obra de Gilberto Freyre no Programa de Pós-Graduação em Sociologia da UFPE. Agradecemos aos colegas e amigos - Eliane Veras, Fernando Mota, Heraldo Souto Maior e Ricardo Santiago - que participavam desse grupo pelas discussões estimulantes. Uma versão preliminar foi apresentada no XXVIII Encontro da Anpocs. Agradecemos também as sugestões recebidas nesse evento. Agradecemos ainda os dois pareceristas anônimos da $R B C S$, que nos ajudaram a enriquecer o texto, e Núbia Mesquita e Luciano Oliveira, que nos ajudaram com os resumos em inglês e francês.

Artigo recebido em outubro/2004

Aprovado em março/2005 debruçaram-se pesquisadores de renome, tais como Araújo (1994, 2000 e 2003), Bastos (1995, 1999a, 1999b, 2000, 2002 e 2003), Vianna (2000), Larreta (2003), Giucci (2003), Souza (2001 e 2003) e Vila Nova (1995a, 1995b, 1995c e 1999), entre outros. Vários aspectos de sua produção têm sido objeto de investigação. Bastos, por exemplo, tem se destacado por investigar as raízes ibéricas do pensamento de Freyre, enquanto Vila Nova procurou mostrar a influência do pensamento norteamericano sobre a obra do referido autor.

No entanto, mesmo considerando a enorme contribuição desses autores, que, em inúmeros momentos, chamam a atenção para o papel das biografias na obra de Freyre, sua concepção sociológica a respeito dos atores sociais, bem como a articulação do nível da microagência com os processos macrossociais mais amplos não têm sido tomadas como objeto de pesquisa. Nem também 
têm sido objeto de pesquisa os problemas teóricos e metodológicos envolvidos nessa operação de redução dos processos macrossociais ao nível microssocial, assim como não há trabalhos, tanto quanto sabemos, acerca do problema reverso que é o da agregação de biografias diversas para efeito de um fenômeno macrossociológico. ${ }^{1}$ Dessa forma, como em mais de uma obra Freyre lança mão de exemplos extraídos de trajetórias individuais para ilustrar a configuração e o desenrolar de um determinado fenômeno social, podemos delinear o foco deste trabalho: investigar a construção dos tipos e das trajetórias de vida individuais, sua relação com os processos macrossociológicos e os problemas de redução e agregação na obra de Gilberto Freyre.

\section{O problema agência-estrutura, as ligações micro-macro e a obra de Gilberto Freyre}

Pode-se afirmar que o tema da relação agência-estrutura é um problema central das ciências sociais, especialmente da sociologia. Com efeito, a forma de entender a relação entre esses dois pólos tem preocupado várias gerações de pensadores na sociologia. Na literatura clássica, as respostas a essa questão assumiram perspectivas diferentes nas obras de Émile Durkheim e Karl Marx, de um lado, e de Max Weber, de outro.

Enquanto os dois primeiros pensadores têm sido identificados, grosso modo, com o coletivismo metodológico, Weber é vinculado ao individualismo metodológico. No primeiro caso, apesar de os indivíduos serem os "portadores" da ação, a eles se atribui pouca importância analítica, uma vez que grupos, classes e instituições representam a concretude dos fenômenos sociais, estes sim merecedores da atenção dos sociólogos. Em contrapartida, no caso do individualismo metodológico, sem que isto signifique abraçar uma visão atomista, há a crença de que todos os fenômenos sociais, em princípio, podem ser reduzidos analiticamente ao nível dos indivíduos. O exemplo mais clássico desse tipo de trabalho é a própria análise desenvolvida por Weber em $A$ ética protestante e o espirito do capitalismo. Não é preciso aqui detalhar o argumento weberiano, basta lembrar que esse autor mostra a ligação entre dois macrofenômenos (a ética protestante e o espírito do capitalismo) pelo exercício de redução ao nível dos indivíduos, isto é, à experiência psicológica - sem que aqui, nunca é demais lembrar, se caia em qualquer psicologismo - vivida por indivíduos concretos.

No caso de Gilberto Freyre, muitos argumentam que, por estar interessado no "homem concreto, de carne e osso", ${ }^{2}$ sua análise sociológica mostraria uma "face" mais compreensiva, por dar atenção ao detalhe e à especificidade das vidas, das culturas, dos espaços geográficos etc. Há, neste tipo de argumento, a sugestão de que a sociologia de Freyre faria pouco uso de tipologias e classificações tendo em vista esse "lado mais humano" (cf. Albuquerque, 2000). Porém, é também nosso objetivo neste trabalho chamar a atenção para o fato de que a análise que Gilberto Freyre faz dos atores sociais não está desprovida de categorizações e do uso de tipologias. ${ }^{3}$

É quase consenso apontar a família como a unidade analítica que percorre a obra de Gilberto Freyre, o que, aliás, o próprio autor afirma em muitos momentos, pois, nas palavras de Souza (2003, p. 70), "a família é a unidade básica, dada a distância do Estado português e de suas instituições, da formação social brasileira". Isto está admiravelmente posto em Casa-grande E senzala e em Sobrados e mucambos (cf. Albuquerque, 2000, p. 46; Samara, 2003; Skidmore, 2003, p. 48). Por outro lado, é também igualmente claro que os processos de institucionalização se dão por intermédio dos indivíduos, vistos por Freyre não somente como conformados por tal processo, mas também como portadores, no sentido de serem agentes ativos, dos costumes e dos valores, já que

A pessoa humana, o homem social ou o socius se afirma não só conservador da herança cultural que lhe é comunicada pela geração anterior, como assimilador de culturas de outros grupos 
que entrem em contato com o seu, e, ainda - sendo maior sua potencialidade - um criador, pelo que acrescente, sozinho ou com poucos outros, à herança do seu grupo ou à cultura de seu tempo (Freyre, 1957, p. 121; cf. também pp. 114, 119, 120, 122, 526, 631, 635 e 636, entre outras).

Por isso, qualquer estudioso familiarizado com a obra de Gilberto Freyre sabe que a análise que ele faz da "história da sociedade patriarcal no Brasil" é fartamente ilustrada por trajetórias de vida de indivíduos, por assim dizer, concretos. Skidmore afirma "que Casa-grande Es senzala não possuía uma história ou acontecimentos dramáticos, heróis ou vilões. Na verdade, havia poucos indivíduos identificáveis em suas seiscentas páginas" (2003, pp. 56-57). Contudo, se a sociologia histórica de Freyre não é uma narrativa de heróis e grandes feitos, um processo de exercício teórico-metodológico se inicia claramente em Sobrados e mucambos e continua, de forma marcante, em Ordem e progresso (cf. Oliveira, 2003), no qual as trajetórias de vida individuais ganham relevo na explicação de processos macrossociais. No dizer de um comentador, Freyre

Articula o homem a sua situação e procura compreendê-lo a partir de suas vivências [...]. Capta nessas vivências inter-relações, interações, interferências, complementaridades, oposições, antagonismos, conflitos que escapam por entre os dedos de tantas disciplinas encarceradas (Albuquerque, 2000, p. 48).

Com efeito, na descrição e na análise da "decadência do patriarcado rural e desenvolvimento urbano" - subtítulo de Sobrados e mucambos, Freyre procura constantemente, quando considera os fenômenos sociais e os diversos fatores ou variáveis envolvidos, ilustrá-los por recorrência à vida de indivíduos que ele conheceu ou que tiveram uma vida intensa e publicamente ligada ao fenômeno analisado.

Nesta obra, ele levanta a questão em termos puramente teórico-metodológicos:

Para acompanharmos a degradação dos valores menos visíveis, característicos da poderosa insti- tuição, é que necessitamos de estudá-la nas suas intimidades mais sutis e esquivas [...]. Elas precisam de ser estudadas em nós mesmos ou nos nossos avós - produtos e reflexos, ao mesmo tempo que animadores, e não apenas portadores, da instituição. Nas pessoas, e não apenas nas formas impessoais em que histórica e sociologicamente se objetivou ou materializou o patriarcado no Brasil (1951b, p. 46).

É nesse sentido que as trajetórias de vida, por exemplo, do Padre Ibiapina, do "velho" Félix Cavalcanti de Albuquerque Mello, de Joaquim Nabuco, de Oliveira Lima, entre outros, aparecem constante e recorrentemente para ilustrar processos macrossociais impessoais, evidenciando a metodologia esboçada por Freyre na introdução à segunda edição de Sobrados e mucambos. A utilização de biografias aparece também na análise que Freyre faz, nesta mesma obra, da relação entre o pai e o filho.

Em relação ao livro Ordem e progresso, esse processo torna-se mais evidente pela metodologia de "depoimentos pessoais" empregada por Freyre (1959a, pp. XIX-CLXIX, mais especialmente, pp. LXXXVI-CXVII; 1959b, p. XLIV).

É importante destacar que esse tipo de "história oral" (cf. Faria, 1998, p. 145; Oliveira, 2003, p. 141) não se refere somente a percepções dos atores sociais entrevistados acerca dos processos sociais por eles vividos, mas também - ou, talvez, principalmente - a suas trajetórias de vida, à moda de uma autobiografia, dado o nível de detalhamento do questionário proposto por Freyre. Tanto isso é verdade que alguns se recusaram delicadamente a responder ao questionário com o argumento de que, se o preenchessem, estariam antecipando as memórias que pretendiam publicar (cf. Freyre, 1959a, p. XLIII). Para Freyre, a personalidade tem um componente coletivo, ou seja, o agente social expressa, além de suas características irredutivelmente individuais, a cultura, os costumes, os valores e a história da sociedade em que viveu. Nesse sentido, o autor afirma, por exemplo, que seus "apontamentos autobiográficos [são] menos referentes a Félix, indivíduo isolado..., [e mais] ao Ca- 
valcanti, chefe de família patriarcal" (1959b, p. CVI, cf. também, 1968b, pp. 51 ss.). A análise dos processos históricos de mudança social, segundo Freyre, passa necessariamente pela ação dos agentes sociais, e esta ação só pode ser capturada pelo método que ele denominou de empático, ${ }^{4}$ o qual pode ser sintetizado, nas palavras do autor:

Daí, para a interpretação de uma época, não ser suficiente o analista dela, desdobrado em intérprete, familiarizar-se com o que no seu decorrer foram fatos; ou apenas valores-coisas. É preciso que ele se torne quanto possível íntimo das relações entre essas pessoas e esses valores; entre as pessoas e os valores imateriais; entre as pessoas e os símbolos mais característicos da época [...]. Daí serlhe necessário buscar penetrar a realidade social através do estudo direto de pessoas tomadas isoladamente (biografias) ou em interação com outras (biografias sociológicas) [...] (1959a, p. XXXII).

Esta interpretação encontra apoio em Vilanova (1999, p. 128) quando afirma que

[...] nisso reside seu [de Freyre] gosto pelo biográfico, sublinhando na personagem individual $o$ ponto de intersecção das correntes de pensamento social, político, literário, ressaltando, dialeticamente, no indivíduo o social, e na dessubjetividade do social o indivíduo historicamente relevante.

Assim, longe de ser um mero exercício de admiração pelo biografado, Freyre dedicou parte razoável de sua obra intelectual à reconstrução das vidas de pessoas por ele consideradas chaves para a compreensão de certos processos sociais pelos quais o Brasil passou ou cujas autobiografias ou meras anotações lhe pareceram de extrema importância para compreender os processos macrossociais. ${ }^{5}$ Vale lembrar as obras, na verdade poderíamos chamá-las de extensas introduções, referentes a Vauthier (1960), Oliveira Lima (1968c), Félix Cavalcanti (1959b), Euclydes da Cunha (1944), entre outros, ${ }^{6}$ no contexto de sua postura metodológica:

A pessoa social, ou humana, ou simplesmente pessoa, é o resultado de processos sociais e de cultura anteriores ao aparecimento do indivíduo e sobreviventes ao seu desenvolvimento individual ou puramente físico-químico e biológico no espaço e no tempo (Freyre, 1957, p. 120).

Isto porque, em obra de cunho mais teórico, Freyre, seguindo Hadley Cantril, aceita a regra teórico-metodológica de que

Não será um simples esforço de empatia projetarse um indivíduo de hoje nos motivos de ação e de comportamento de um indivíduo de área e época diversas da sua, mas um esforço em que a empatia precisará de ser acompanhada o mais possível de conhecimento dos antecedentes e valores de cultura que, na pessoa remota ou distante que se procure estudar sociologicamente - um Antônio Conselheiro, por exemplo - tenham se interiorizado se não no seu eu - o que tenderia a particularizar todo esforço de compreensão de tal pessoa em biografias - no seu "nós" psicocultural e histórico-regional [...]. Seriam considerados, portanto, ao mesmo tempo, "instintos", valores suscetíveis de interiorização e variação individual e normas do grupo ou da época inteira. Que todos formam o "nós" de um grupo ou figura de uma geração que não se avalie a si próprio - e aja dentro dessa auto-avaliação - tendo por ponto de referência as normas de sua sociedade particular ou de seu tempo (Idem, pp. 514-515).?

No entanto, talvez seja em uma obra relativamente desconhecida no Brasil, intitulada Contribuição para uma sociologia da biografia (1968b), ${ }^{8}$ que Freyre leva a cabo, a nosso ver, uma análise magistral, em meio aos floreios verbais de que tanto gostava, da interação entre biografia individual e processos macrossociais. ${ }^{9}$ Neste trabalho, o autor analisa a vida do capitão-general Luiz de Albuquerque, governador da província de Mato Grosso no fim do século XVII.

Luiz de Albuquerque, um nobre português, que, tendo se destacado na luta contra os espanhóis, foi enviado ao Brasil para administrar aquela inóspita província, que estava ameaçada pelas incursões dos espanhóis. Durante o seu governo, Luiz de Albuquerque, além de obras notáveis de engenharia (por exemplo, a construção de fortes com materiais trazidos da Europa em bar- 
cas através de rios parcamente navegáveis), também promoveu festas e saraus e recolheu vasto material sobre a fauna e a flora do Novo Mundo.

Pois bem: para Freyre, este capitão-general representa um tipo sociológico por excelência do que ele chama homem luso-tropical. Freyre, então, vasculha as anotações - uma espécie de diário - deixadas por Luiz de Albuquerque. E o interessante é que antes de empreender a análise, Freyre abre o livro com uma epígrafe retirada de A imaginação sociológica, de C. Wright Mills: "a imaginação sociológica [...] nos permite compreender a história e a biografia, e as relações entre as duas dentro da sociedade". ${ }^{10}$

No entender de Freyre,

Com esse material [as anotações de Albuquerque], além de autobiográfico, histórico, supõe o Autor [Freyre] ter reunido, não só dessa fonte como de arquivos públicos [...], um conjunto de informes sociològicamente significativos que concorram para uma "autobiografia colectiva", de tipo como que weberianamente "ideal"..., do homem português e, neste caso, transformado - ou em fase aguda de transformação, como foi a aventura de Luiz de Albuquerque em Mato Grosso - em homem luso-tropical (1968b, p. 29; cf. também p. 97).

No entanto, Freyre, além de falar em "tipo como que weberianamente "ideal", refere-se também a Luiz de Albuquerque como um tipo

[...] simbólico e, por conseguinte, como indivíduo que, pelos seus característicos de personalidade e pelos seus actos e seu comportamento durante o período de sua existência mais històricamente significativo [...], contribuiu para a ampliação de uma autobiografia colectiva antes dele já em desenvolvimento: a da transformação, no espaço e no tempo, do homem apenas português em homem luso-tropical (Idem, p. 49; cf. também pp. 53, 72-73).

Nesse sentido, Freyre considera ser Luiz de Albuquerque um tipo sociológico privilegiado para a análise do fenômeno macrossocial do lusotropicalismo, pois que o capitão-general represen- tava, ao mesmo tempo, um Albuquerque; um hispano ou ibérico; um português fidalgo, católico e - contradição - pombalino; um oficial-engenheiro do Exército português etc. (Idem, p. 54). No que ele acrescenta que o seu estudo deste oficial português

[...] pretende sugerir de Luiz que ele teria sido parte de um processo històricamente sociológico ou sociològicamente histórico, em que a sua personalidade teria funcionado, repetindo outras do mesmo tipo: a de português fidalgo em acção construtiva no trópico (Idem, p. 99).

Ou, ainda, quando ele reafirma, de forma mais clara, adiante:

É talvez o que mais se deva distinguir na personalidade e na acção que Luiz desenvolveria [...]: o facto de nessa personalidade e nessa acção terem-se juntado a constantes de português velho assimilações de técnicas e saberes norte-europeus, novos e até novíssimos, por ele postos a serviço de vasta empresa luso-tropical, iniciada sob a mesma congregação de actividades: a militar, completada pela técnica; a religiosa, completada pela científica; a intuitiva, pela racional (Idem, p. 127).

\section{Micro e macro na sociologia: indivi- dualismo metodológico, redução e superveniência}

A discussão que vimos empreendendo permite, agora, fazer uma relação com um tema aparentemente distante das preocupações freyrianas: a articulação entre os níveis micro e macro da explicação social. Em que medida podemos supor que existe, em Gilberto Freyre, um tipo de explicação dos fenômenos sociais que está relacionado a esse problema metodológico?

Podemos partir da perspectiva de um posicionamento metodologicamente individualista. $\mathrm{O}$ individualismo metodológico deve ser compreendido aqui em sua vertente explicativa, ou seja, uma forma de reducionismo, uma injunção para explicar fenômenos sociais complexos em termos de seus 
componentes individuais, tanto quanto a biologia tenta explicar os fenômenos celulares em termos dos seus componentes moleculares (Elster, 1983).

Este tipo de reducionismo levar-nos-ia a explicar fenômenos complexos de forma simples. O reducionismo, portanto, seria a mais importante estratégia da ciência, tendo levado ao surgimento de disciplinas como a biologia molecular e a físico-química. No entanto, no âmbito das ciências sociais, é preciso concordar com Jon Elster e admitir que estamos longe de uma psicologia social ou de uma sociologia psicológica que tenha conseguido efetuar uma redução completa. Não haveria objeções a essa redução, mesmo que, contemporaneamente, ela só possa ser parcial (idem) ${ }^{11}$ Ressalte-se que esse projeto reducionista está em consonância com a posição de Donald Davidson (1980), qual seja, de que não devemos buscar a tradução de estados mentais dos indivíduos em termos de seus estados cerebrais. O que consideramos possível nas ciências sociais é a redução dos fenômenos sociais aos seus componentes individuais e/ou psicológicos. Mas, de acordo com Little (1991), pelo menos duas objeções podem ser levantadas contra projetos radicais de redução:

- A filosofia da ciência contemporânea reconhece que em várias áreas da ciência o reducionismo não é uma exigência factível, pois existem dificuldades para a obtenção de leis no nível exigido pela estratégia reducionista.

- Argumentos pragmáticos asseveram que as explicações nos níveis mais altos da "organização" podem ser, muitas vezes, melhores do que aquelas dos níveis inferiores, quando as explicações dos níveis superiores estão em correspondência com regularidades empíricas nesse nível (e não nos inferiores) ou quando a explicação nos níveis mais baixos implica dificuldades e custos computacionais tão elevados que se tornam obstáculos tanto à explicação como à predição.

Nessa mesma linha, Garfinkel e Papineau (apud Bhargava, 1992) argumentam que os obje- tos da explicação macro e micro são diferentes. $\mathrm{O}$ princípio da microrredução - para cada objeto existem duas explicações, uma reduzida à outra não é possível porque resultaria em explicações não do mesmo objeto, mas de dois objetos completamente separados. Teríamos, portanto, duas explicações irredutíveis, e a microrredução falharia. Esses autores não negam que os objetos têm microexplicações ou microfundamentos, mas defendem que as explicações no nível micro constroem seus objetos de forma diferente, não competindo assim com as explicações no nível macro. As microexplicações seriam incapazes, portanto, de ameaçar a autonomia das macroexplicações.

Bhargava (1992) chega a afirmar que uma visão pragmática nos mostra que uma explicação que postula uma relação entre fatos existentes completamente independentes dos indivíduos que os analisam não existe. A explicação tem um componente do qual não se pode escapar: é construída com propósitos epistêmicos específicos.

$\mathrm{O}$ argumento pragmático afirma que tanto o não individualista quanto o individualista têm razão ao afirmar que as explicações causais são indispensáveis.

Um outro tópico de especial relevância no debate sobre o Individualismo Metodológico, como projeto de redução, é a questão posta por Bhargava a respeito de indivíduos típicos ou efetivos (particulares) como unidades de redução de fenômenos sociais típicos ou efetivos.

Esse autor defende a idéia de que reduções devem envolver indivíduos típicos, não qualquer conjunto de indivíduos que, em um momento qualquer, participam da construção de uma entidade social em questão. Todas as microrreduções envolvem entidades típicas em diferentes níveis de generalidade e poderiam não só envolver quaisquer entidades particulares que, em um determinado momento, acabam constituindo a macroentidade. Uma explicação em termos de tais entidades particulares, chamada de microexplicação, pode ser válida, mas não é uma microrredução.

Segundo Bhargava, a microrredução deve encerrar uma explicação em termos de indivíduos 
que tipicamente conformam um fenômeno social típico e não envolve a explicação de entidades sociais particulares.

Tomemos um exemplo no campo das ciências naturais: a relação água- $\mathrm{H}_{2} \mathrm{O}$. Parte-se do suposto de que existem diferenças entre amostras específicas e amostras típicas de água. Qualquer amostra particular de água contém um grande número de impurezas. Então, uma amostra particular de água nunca poderá ser identificada com os constituintes "originais" da água. Se, analogamente, imaginamos todos os atributos contingentes dos indivíduos, um grande número de "impurezas" também ocorrerá. Então, a redução da entidade social para esses indivíduos efetivos poderá não funcionar nem ser desejável.

Uma objeção plausível à discussão realizada logo acima é que, no mundo social, não existem dois indivíduos iguais, o que tornaria a redução, através de elementos típicos, aparentemente, problemática. Em outros termos, os componentes psicológicos dos indivíduos podem variar de uma forma que não seria captada pela atribuição de elementos psicológicos típicos (os microcomponentes) a eles. Assim, nas ciências sociais, esta diferença pode ser significativa, pois a substituição dos atributos "encontrados" pelos típicos pode mudar a identidade de um indivíduo humano. Haveria diferenças até entre um conjunto de propriedades típicas e todas as propriedades, as quais apenas de modo contingente pertencem a indivíduos.

Finalmente, há uma questão que pode ser derivada da obra de Alan Ryan (1977). De acordo com este autor, não podemos sustentar a idéia de que a verdade dos enunciados sociológicos depende da verdade dos enunciados psicológicos. Segundo Ryan, "o fato de que certas espécies de generalização sociológica não seriam verdadeiras caso não houvesse várias verdades correspondentes da psicologia, simplesmente não pode mostrar que o significado de uma determinada proposição é idêntico ao de outra" (1977, p. 242). Suponha-se que um enunciado sociológico holístico tenha o propósito de que um sistema capitalista necessite de uma estrutura normativa adequadamente im- posta de atitudes universalistas orientadas para o empreendimento econômico, e que a existência do capitalismo nos Estados Unidos possa ser explicada em termos dessa necessidade do sistema satisfazer-se. As generalizações psicológicas correspondentes a tal explicação não fariam menção a coisas tais como as necessidades do sistema, mas presumivelmente referir-se-iam à impossibilidade do indivíduo ter a disposição de fazer coisas, essenciais ao comportamento capitalista, a menos que ele tenha também as várias finalidades e objetivos em que se resumem seus valores universais orientados para o empreendimento. Segundo Ryan, "a verdade sociológica, se é que existe, reside nas verdades psicológicas, se é que existem, sem lhes ser idêntica" (Idem, ibidem).

A posição defendida por Ryan parece aproximar-se do conceito de "superveniência", proposto por Little (1991). A idéia deste autor é que fenômenos sociais têm superveniência sobre as ações e as crenças individuais, permitindo-nos absorver a exigência de que os fenômenos sociais são completamente dependentes dos conjuntos de indivíduos, sem os perigos da redução radical. Ao contrário da tese radical, podemos conviver com o fato de que os fenômenos sociais têm superveniência sobre os fenômenos individuais, mas isto não implica que os conceitos e as explicações sociais necessitem de redução a conceitos e explicações no nível individual, que transformem em exigência metodológica a redução, que é uma estratégia analítica, mas não exclusiva.

Essa breve discussão sobre o individualismo metodológico - a redução, suas possibilidades e seus inconvenientes - deve ser conectada com a obra de Gilberto Freyre. É certo que sua obra é pródiga em utilizar as trajetórias de indivíduos concretos para ilustrar processos de mudança social: políticos, proprietários rurais, médicos, advogados, padres, donas de casa etc. são elementos constituintes da narrativa analítica freyriana. Assim, a questão central que se anuncia é: Em que medida a utilização de biografias e de trajetórias de vida individuais insinua uma posição metodologicamente individualista ou mesmo um projeto de 
redução? Ou haverá, meramente, a descrição de processos sociais "ilustrados" por trajetórias individuais, o que configuraria a aproximação com a idéia de superveniência proposta por Little? A utilização de indivíduos históricos concretos permite a afirmação de que a obra de Freyre tem a preocupação de fundamentar, no nível da ação individual, processos sociais mais amplos?

Tais questões servirão como referência para o desenvolvimento da análise que faremos de parte da obra de Gilberto Freyre.

\section{Os fenômenos macrossociais nas biografias em Gilberto Freyre}

A análise sociológica de Freyre é pautada por uma recorrente operação metodológica, qual seja, a articulação dos processos sociais mais gerais com a vida concreta de alguns personagens da história brasileira. Ora ele invoca a vida de Joaquim Nabuco, ora a do Pe. Ibiapina, ora a de personagens diversos.

Um dos fenômenos macrossociais analisados por Freyre em Sobrados e mucambos - e que se anuncia no subtítulo da obra - é o da decadência do patriarcado rural. Com o crescente processo de diferenciação social da sociedade brasileira, Freyre mostra como lentamente o patriarcado rural brasileiro vai se desmoronando, ao mesmo tempo em que ocorre a emergência da sociedade urbana. Muitos dos patriarcas rurais se mudam do campo para a cidade e, simbolicamente, há a crescente substituição da casa-grande pelo sobrado urbano. Esse processo ocorre seja pelas possibilidades de consumo e pelos acontecimentos mundanos existentes nas cidades, em contraposição à vida monótona no campo, seja pela decadência econômica desta classe social. Embora longa, vale a pena reproduzir a seguinte passagem:

Já o pai de Ibiapina rebelara-se contra a decisão da família de fazê-lo padre, fugindo com uma moça [...] nas vésperas de partir de Sobral para o seminário de Olinda. Desintegração do patriarca$d o$. Enfraquecimento do poder dos patriarcas. Re- belião dos filhos contra os pais, ao mesmo tempo que das mulheres contra os homens, dos indivíduos contra as famílias, dos súditos contra os reis. O que indica que, na história de uma família ou de uma personalidade característica, se resume muitas vezes a história de uma sociedade se procurarmos considerá-la e interpretá-la não só econômica como cultural e psicologicamente [...]. Foi, aliás, o que o sr. Diogo de Melo Meneses e eu esboçamos na seleção de material [...] que constitui o livro de memórias do velho Félix Cavalcanti de Albuquerque [...]. Valendo-nos principalmente de relíquias e apontamentos de família, procuramos resumir a vida de um indivíduo nascido menino de engenho, opulento engenho Jundiá - mas que as circunstâncias degradaram em morador de casa de sítio e de sobrado de aluguel; e em patriarca decadente, forçado, para conservar o prestígio do nome de família, a empregar os filhos bacharéis na Alfândega e a tolerar filhas, professoras de meninos (Freyre, 1951b, pp. 9596, grifos nossos).

Freyre trata de um processo macrossociológico extremamente complexo dado o número inferimos - de variáveis envolvidas. Note-se que é o próprio Freyre que, teórica e metodologicamente, aumenta a complexidade do problema ao chamar a atenção do leitor para os aspectos culturais e psicológicos, além dos fatores econômicos, envolvidos. Mesmo assim, sua análise vai no sentido de passar direta e imediatamente desse nível mais geral para a esfera da vida concreta: a do velho Félix Cavalcanti. Nesse sentido, parece haver a crença de que indivíduos concretos - não abstratos ou típicos - são portadores dos processos sociais. Em outras palavras, o processo social mais geral e, de certa forma, abstrato, que é a decadência do patriarcado rural, revela-se em sua inteireza na vida do patriarca decadente que foi o velho Félix. A transposição do nível macro para o nível micro é direta, sem intermediações. Porém, há de se atentar para o fato de que Freyre faz uma análise à parte de outros fenômenos sociais que, na realidade, estão subordinados ao processo macrossocial. Afirma nosso autor que:

O regime de economia privada dos sobrados, em que se prolongou quanto pôde a antiga economia 
autônoma, patriarcal das casas-grandes, fez do problema do abastecimento de víveres e de alimentação das famílias ricas, um problema de solução doméstica ou particular [...] [: foi] o caso de Félix Cavalcanti de Albuquerque (Idem, p. 363).

Embora formalmente subordinada ao processo de decadência da economia baseada no patriarcalismo rural, a questão do abastecimento de víveres é tratada como um fenômeno em si. Se pensarmos no esquema

\section{Processo Macrossocial $\rightarrow$ Processo Mesossocial $\rightarrow$ Processo Microssocial}

veremos que Freyre não trabalha dentro dessa lógica, mas de forma que os dois níveis de maior abrangência analítica, independentes entre si, são conectados às biografias de personagens concretos. A vida do velho Félix ilustra simultaneamente os processos meso e macrossociais sem que façam parte de uma operação teórico-metodológica, como ilustrado no fluxo macro-meso-micro aludido.

A mesma operação teórico-metodológica é feita por Freyre na análise de certos fenômenos sociais em que utiliza o exemplo da vida de Joaquim Nabuco para "provar" sua tese.

Lembremos aqui uma das mais interessantes hipóteses de Freyre com relação à formação da família brasileira: a de que, no contexto do patriarcalismo rural, o patriarca se posicionava em franca oposição à sua mulher e aos seus filhos. Em outras palavras, o menino estava mais próximo de sua mãe, porque, assim como ela, era um oprimido. Além disso, muitas crianças, neste contexto, foram educadas em casa - e não em uma escola -, muitas vezes por suas madrinhas, numa extensão do fenômeno social a que Freyre denominou maternalismo. Observe-se, de passagem, que esse fenômeno está, analiticamente, subordinado ao processo social mais geral do patriarcalismo rural.

Pois bem: para dar evidências empíricas que provem o seu ponto de vista, Freyre aponta para o exemplo de Joaquim Nabuco, que teria, segundo ele, vivenciado todo esse processo (Idem, pp. $82,319,535)$. Freyre ainda utiliza o exemplo da tra- jetória de vida de Joaquim Nabuco para demonstrar que a estratificação social brasileira no século XIX era resultado de múltiplas variáveis. Em suas próprias palavras:

Mais forte que a condição de raça, como condição ou base de prestígio, eram evidentemente a condição de classe e a própria condição de região de origem ou residência do indivíduo. Não nos esqueçamos de que, em Pernambuco, quem fosse proprietário de largas terras de cana na chamada zona da mata era como quem fosse grande senhor de engenho na zona baiana do recôncavo ou grande estancieiro no Rio Grande do Sul: um privilegiado pela região física e pelo espaço social de sua propriedade ou de sua fazenda. Vantagens que, ligada à de raça branca, à de classe superior e à de sexo chamado forte, favorecia o indivíduo com as condições ideais de bem-nascido e de bem-situado na sociedade [...] o caso de Joaquim Nabuco, bem nascido como ninguém no Brasil de há cem anos e desde pequeno bem-situado como ninguém, cultural e socialmente, na sociedade brasileira do Segundo Reinado e do começo da República (Idem, p. 687).

Um outro fenômeno interessante analisado por Freyre é o cenário cultural nesse período de transição tratado em Sobrados e mucambos. No processo de decadência do patriarcalismo rural brasileiro, Freyre atribui um peso considerável ao fato de que os valores dessa estrutura social começam a se desagregar graças ao surgimento de novos valores culturais, eminentemente urbanos, cultivados pelos novos bacharéis de formação cosmopolita, isto é, européia. Com efeito, Freyre acentua que a decadência do patriarcado rural não se deve somente à decadência de um tipo de economia baseada na escravidão, mas também ao crescimento dos centros urbanos e ao surgimento de uma classe burguesa, de novas profissões e da ascensão dos bacharéis, muitos deles mulatos. Como muitos desses novos personagens tiveram formação acadêmica em importantes universidades européias (Montpellier e Coimbra, principalmente), trouxeram consigo valores socioculturais correntes no cenário cultural europeu de então.

Assim é que muitos dos nossos literatos 
abraçaram os ideais românticos não apenas como valores estéticos, mas também como modo de vida - diz Freyre que o Pe. Gama se alarmava com a aparência doentia dos jovens do seu tempo. Vários são os exemplos de escritores que morreram antes dos 25 anos - Álvares de Azevedo, Casimiro de Abreu, Junqueira Freire, entre outros, que tinham como ideal de vida uma certa morbidez por morrer jovem.

Concomitante a essa mudança de valores, pode-se observar outros dois processos sociais em evidência: a ascensão do jovem bacharel, por um lado, e a do mulato, por outro. Muitas vezes esses dois processos foram vividos pelo mesmo sujeito jovem bacharel e mulato, que começava a ocupar o lugar dos mais velhos. Gradativamente, os novos bacharéis foram assumindo cargos importantes no aparato estatal (Idem, p. 240) ou mesmo o comando dos negócios dos patriarcas através do casamento com as filhas desses senhores. Esses fenômenos sociais estão todos ligados e nada se fez sem atritos. Por mais longo e imperceptível que seja um processo de mudança social, na concepção de Freyre, este não se dá de forma suave e sem impacto na vida das pessoas envolvidas. Assim é que emerge da análise freyriana a idéia de que havia um certo desconforto psíquico, quase físico, por parte dos bacharéis, sobretudo dos bacharéis mulatos, alguns dos quais terminaram por aderir, explica Freyre, a movimentos revolucionários.

Em suma, temos aqui três fenômenos macrossociológicos: ascensão dos jovens bacharéis, ascensão do mulato (processos de mobilidade social) e surgimento de um conjunto de valores culturais urbanos baseado nos ideais românticos (processo de mudança cultural). Freyre os exemplifica fartamente com a descrição de diversas histórias de vida, mas, para alguns dos aspectos desses fenômenos, seu exemplo mais caro é o poeta Gonçalves Dias.

Com efeito, a vida ímpar de Gonçalves Dias serviu para que Freyre pudesse ilustrar, a um só tempo, esses fenômenos que, na sua avaliação, ocorreram concomitantemente ao processo de decadência do patriarcalismo rural. Gonçalves Dias era -
Freyre enfatiza várias vezes (Idem, pp. 240, 284, 975976) - um bacharel mulato e poeta romântico que morreu aos 40 anos. Em outras palavras, Freyre opera mais uma vez o artifício teórico-metodológico que vimos anunciando neste trabalho: a ligação direta entre um ou mais fenômenos macrossociológicos e a trajetória singular de um determinado indivíduo.

\section{Considerações finais}

Afinal, podemos dizer que a redução é um procedimento metodológico utilizado na obra de Gilberto Freyre? Em outras palavras, os processos sociais complexos são explicados em termos dos seus componentes individuais? Mesmo se considerarmos as objeções de Little e Elster, de que não se pode encontrar leis nas ciências sociais, e ficarmos apenas com mecanismos como substitutos das leis, em Freyre, haveria uma conexão dos mecanismos no nível macro com mecanismos no nível micro? E, finalmente, se, em Freyre, os indivíduos que "exemplificam" os processos sociais não são indivíduos típicos, mas concretos, inviabilizando a idéia de que a explicação em Freyre se assemelha à redução, podemos falar então de superveniência na obra deste autor?

Os argumentos desenvolvidos na parte 4 deste trabalho revelam como Freyre conecta processos macrossociais, como a decadência do patriarcado rural, a estratificação social em Pernambuco no século XIX e a ascensão social dos bacharéis e dos mulatos, com figuras históricas Félix Cavalcanti de Albuquerque, Joaquim Nabuco e Gonçalves Dias, respectivamente. Junto a estes e outros protagonistas da história, dezenas de tipos sociais coadjuvantes, típicos ou concretos, aparecem com freqüência na explicação freyriana, seja em Casa-grande \& senzala, Sobrados e mocambos, seja n'O velho Félix e suas "Memórias de um Cavalcanti".

Freyre parece utilizar, de forma combinada, na tentativa de articular o nível mais abrangente de sua explicação a trajetórias de vida dos indiví- 
duos tomados como exemplo, princípios que lembram ora um processo de redução mais rigoroso (fenômeno macrossingular - indivíduos típicos), ora uma articulação mais superficial das trajetórias particulares com fenômenos macrossociais aludidos (fenômenos sociais macroparticulares indivíduos particulares). Contudo, certamente a inclinação freyriana por uma sociologia da biografia, aliada a uma despreocupação metodológica em termos dos cânones explicativos, parece indicar princípios que mais se aproximam de uma microexplicação de certa forma enfraquecida - em que os indivíduos típicos são apenas coadjuvantes, predominando as figuras históricas exemplares, quase que portadoras típicas dos processos sociais que o autor quer entender e explicar -, do que propriamente de uma microrredução, se seguirmos as distinções propostas por Rajeev Bhargava e apresentadas na parte 2 deste artigo.

Se, por um lado, a opção metodológica do autor perde em rigor analítico, por outro, as objeções que levantamos quanto à factibilidade de um projeto de redução radical como estratégia válida para as ciências sociais parecem legitimar, em algum grau, a escolha de Freyre por uma modalidade de associação entre processos sociais e indivíduos não-típicos, ou, em outros termos, biografias individuais. Essa posição daria conta das sutilezas e das nuanças que a variação individual comporta, evitando a padronização que uma opção por indivíduos típicos carregaria. Ademais, em Freyre, a explicação sociológica é também histórica, contingencial. Nesse caso, nem os processos macrossociais seriam típicos.

Se o que dissemos acima é verdadeiro, e não temos efetivamente redução ao nível micro em Freyre, a idéia de superveniência, aqui proposta a partir de algumas das idéias de Little e Ryan, parece deixar um campo mais aberto para o enquadramento da explicação freyriana. Pois os microprocessos psicossociais específicos identificados nos inúmeros biografados de Gilberto Freyre podem articular-se, com menos problemas, aos mecanismos sociais mais amplos propostos pelo autor sem que, necessariamente, sejam os exemplares por excelência daqueles processos. A explicação dos "casos", portanto, ilustra e exemplifica os "processos", sem contudo esgotá-los. Menos do que redução, a explicação em Freyre se configura como uma forma não-intencional de superveniência que, articulando os níveis macro e micro de uma forma relativamente frouxa, aponta, ainda que de maneira incipiente, para os temas da agência e da estrutura.

\section{NOTAS}

1 A maior parte dos trabalhos sobre a obra de Freyre concentra a atenção nos processos sociais empíricos em si, mais do que na problematização acerca da construção de um modelo teórico-metodológico para a explicação freyriana.

2 O termo "homem de carne e osso", correlato ao de "homem concreto", sem qualquer conotação biológica, é largamente usado por vários comentadores de Freyre (ver, por exemplo, Cláudio Aguiar, 1999) para acentuar o fato de que a concepção freyriana de homem não se reduz a tipologias sociologizantes.

3 Estamos atentos para as complexas relações que se estabelecem entre a perspectiva sociológica e a perspectiva histórica nas ciências sociais e na relevância que esse tópico tem na obra de Gilberto Freyre, em especial. No entanto, o foco analítico deste trabalho é outro, a saber, as relações entre processos sociais e seus componentes microssociológicos na obra de Gilberto Freyre.

4 Cf. Freyre (1968b, p. 101), em que se pode observar claramente sua tese. Ver também a esse respeito, C. Aguiar (1999, p. 73); R. Aguiar (1999, p. 115); Bastos (1995, p. 71; 1999a, p. 320; 1999b, pp. 328, 335, 336-337, 345); Ribeiro (2001, pp. 34-35); Saldanha (1999, pp. 34, 36-37); Sevcenko (2001, pp. 49, 53).

5 Vale lembrar que Freyre também dedicou páginas a pessoas que ele admirava e que nada tinham a ver com o Brasil. Nesse caso, inclui-se o opúsculo sobre Walt Whitman, poeta que ele tanto admirava, 
e os capítulos sobre Amy Lowell e H.L. Mencken, entre outros.

6 Freyre também incentivou o trabalho de associados e conhecidos. Entre eles, o bonito e bucólico livro de Bello (1985), testemunho de alguém que vivenciou o tipo de transição social que intelectualmente sempre preocupou Freyre.

7 É nítida a proximidade entre o procedimento empático proposto por Freyre e aquilo que se convencionou chamar de Verstehen nas ciências sociais.

8 A única edição brasileira, segundo dados da homepage da Fundação Gilberto Freyre, foi publicada em 1978 pela Fundação Cultural de Mato Grosso. A edição usada aqui é a portuguesa publicada em 1968. Este livro, tal como Um engenheiro francês no Brasil, em sua segunda edição, é dividido em dois volumes, sendo o primeiro dedicado à análise do material por Freyre, e o segundo, às notas de um diário deixado por Luiz de Albuquerque.

9 O livro Mozart: sociologia de um gênio, de Norbert Elias (1995), é um exemplo de tratamento sociológico de uma biografia individual.

10 A tradução deste e de outros trechos, quando não expressamente indicado, é de nossa autoria.

11 Há, curiosamente, uma aproximação aparentemente estranha entre as idéias de Elster e as percepções gerais de Gilberto Freyre acerca da necessária introdução de elementos psicológicos na explicação sociológica. No entanto, Freyre busca evitar a subordinação da sociologia à psicologia, propondo uma fundamentação antropológica e histórica da primeira, dada sua natureza de ciência da cultura. É possível também identificar uma clara afinidade - consciente ou não - de tais idéias com elementos da metodologia weberiana (cf. Freyre, 1951b, pp. 49-51; 1957, pp. 234-235).

\section{BIBLIOGRAFIA}

AGUIAR, Cláudio. (1999), "O homem 'intrahistórico' em Casa-grande \& senzala”, in $\mathrm{F}$.
Quintas (org.), A obra em tempos vários, Recife, Massangana.

AGUIAR, Roberto. (1999), "Dominação e consenso em Gilberto Freyre", in F. Quintas (org.), A obra em tempos vários, Recife, Massangana.

ALBUQUERQUE, Roberto C. de. (2000), Gilberto Freyre e a invenção do Brasil. Rio de Janeiro, José Olympio.

ALEXANDER, Jeffrey C. (1988), Action and its environment. Nova York, Columbia University Press.

\& GIESEN, Bernhard. (1987), "From reduction to linkage: the long view of the micro-macro link", in J. C. Alexander et. al. (orgs.), The micro-macro link, Berkeley/Los Angeles/Londres, University of California Press.

ARAÚJO, Ricardo B. de. (1994), Guerra e paz: Casa-grande E senzala e a obra de Gilberto Freyre nos anos 30. Rio de Janeiro, Editora 34.

(2000), "Sobrados e mucambos e Raízes do Brasil", in M. do C. T. de Miranda (org.), Que somos nós? 60 Anos de Sobrados e mucambos. Recife, Massangana.

. (2003). "Raios e trovões: plasticidade, excesso e modernidade na obra de Gilberto Freyre", in J. C. de C. Rocha (org.), Nenhum Brasil existe, Rio de Janeiro, Editora da Uerj/Topbooks/UniverCidade.

BASTOS, Elide R. (1995), "Gilberto Freyre e as ciências sociais no Brasil”. Estudos de Sociologia (Recife), 1 (1): 63-72.

(1999a), "Gilberto Freyre e o não europeísmo da sociedade ibérica”, in $\mathrm{F}$. Quintas (org.), A obra em tempos vários, Recife, Massangana.

(1999b). "Gilberto Freyre e o pensamento hispânico", in F. Quintas (org.), $A$ 
obra em tempos vários, Recife, Massangana.

(2000), "O tema da decadência em Sobrados e mucambos", in M. do C. T. de Miranda (org.), Que somos nós? 60 anos de Sobrados e mucambos, Recife, Massangana.

(2001), "Gilberto Freyre: Casa-grande $\varepsilon$ senzala", in L. D. Mota (org.), Introdução ao Brasil: um banquete no trópico, 3 ed., São Paulo, Senac, vol. 1.

(2002), "Gilberto Freyre: Ordem e progresso”, in L. D. Mota (org.), Introdução ao Brasil: um banquete no trópico, 2 ed., São Paulo, Senac, vol. 2.

(2003). Gilberto Freyre e o pensamento hispânico: entre Dom Quixote e Afonso El Bueno. São Paulo, Anpocs/Sumaré/Edusc.

BELLO, Júlio. (1985), Memórias de um senhor de engenho. 3 ed. Recife, Fundarpe.

BERTAUX, Daniel. (1995), "Social genealogies commented on and compared: an instrument for observing social mobility processes in the 'longue durée'". Current Sociology, 43 (2/3): 69-88.

BHARGAVA, Rajeev. (1992), Individualism in social science. Oxford, Clarendon Press.

BHASKAR, Roy. (1975), A realist theory of science. Londres, Verso.

BOUDON, Raymond \& BOURRICAUD, François. (1993), Dicionário crítico de sociologia. Trad. M. Letícia G. Alcoforado e Durval Ártico. São Paulo, Ática.

BUNGE, Mario. (1999), The sociology-philosophy connection. Londres, Transaction Books.

CHACON, Vamireh. (2000), "O homem na cidade, segundo Sobrados e mucambos - origens da polis brasileira: uma teoria política em Sobrados e mucambos", in M. do C. T. de Miranda (org.), Que somos nós? 60 anos de Sobrados e mucambos, Recife, Massangana.

COLEMAN, James S. (1987), "Microfoundations and macrosocial behavior", in J. C. Alexander et al. (orgs.), The micro-macro link, Berkeley/Los Angeles/Londres, University of California Press.

DAVIDSON, Donald. (1980), Essays on actions and events. Oxford, Oxford University Press.

ELIAS, Norbert. (1994), O processo civilizador I: uma bistória dos costumes. Tradução de Ruy Jungmann. 2 ed. Rio de Janeiro, Jorge Zahar.

. (1993). O processo civilizador II: formação do Estado e civilização. Trad. Ruy Jungmann. Rio de Janeiro, Jorge Zahar.

. (1995). Mozart: sociologia de um gênio. Trad. Sérgio Góes de Paula. Rio de Janeiro, Jorge Zahar.

ELSTER, Jon. (1983), Explaining technical change. Cambridge, Cambridge University Press.

EVANS, Mary. (1993), "Reading lives: how the personal might be social". Sociology, 27 (1): 5-13.

FARIA, Lina Rodrigues de. (1998), "Histórias de vida: o pioneirismo de Gilberto Freyre". Sociedade e Estado, 13 (2): 143-164.

FONSECA, Edson Nery da. (1983), Um livro completa meio século. Recife, Massangana.

FREYRE, Gilberto. (1944), Perfil de Euclydes e outros perfis. Rio de Janeiro, José Olympio.

(1947), Interpretação do Brasil: aspectos da formação social brasileira como processo de amalgamento de raças e culturas. Trad. Olívio Montenegro. Rio de Janeiro, José Olympio.

(1948), Ingleses no Brasil: aspectos da influência britânica sobre a vida, a paisa- 
gem e a cultura do Brasil. Rio de Janeiro, José Olympio.

(1951a), Nordeste: aspectos da influencia da canna sobre a vida e a paizagem do Nordeste do Brasil. 2 ed. Rio de Janeiro, José Olympio.

(1951b), Sobrados e mucambos: decadência do patriarcado rural e desenvolvimento do urbano. 2 ed. Rio de Janeiro, José Olympio.

(1952), Casa-grande E senzala: formação da familia brasileira sob o regime de economia patriarcal. 7 ed. Rio de Janeiro, José Olympio.

(1957), Sociologia: introdução ao estudo dos seus princípios. 2 ed. Rio de Janeiro, José Olympio.

(1959a), Ordem e progresso: processo de desintegração das sociedades patriarcal e semipatriarcal no Brasil sob o regime de trabalho livre, aspectos de um quase meio século de transição do trabalho escravo para o trabalbo livre e da Monarquia para a República. Rio de Janeiro, José Olympio.

(1959b), O velho Félix e suas "Memórias de um Cavalcanti". 2 ed. Rio de Janeiro, José Olympio.

(1960), Um engenheiro francês no Brasil. 2 ed. Rio de Janeiro, José Olympio.

(1968a), Como e porque sou e não sou sociólogo. Brasília, Editora da Universidade de Brasília.

(1968b). Contribuição para uma sociologia da biografia: o exemplo de Luís de Albuquerque, governador de Mato Grosso, no fim do século XVII. Lisboa, Academia Internacional da Cultura Portuguesa.

(1968c), Oliveira Lima, Don Quixote gordo. Recife, Editora da UFPE.
(1979). Heróis e vilões no romance brasileiro: em torno das projeções de tipos sócio-antropológicos em personagens de romances nacionais do século XIX e do atual. São Paulo, Cultrix.

GIESEN, Bernhard. (1987), "Beyond reductionism: four models relating micro and macro levels", in J. C. Alexander et al. (orgs.), The micro-macro link, Berkeley/Los Angeles/Londres, University of California Press.

GIUCCI, Guillermo. (2003), "Gilberto Freyre e o (pós)modernismo", in E. V. Kosminsky et al. (orgs.), Gilberto Freyre em quatro tempos, São Paulo/Bauru, Unesp/Edusc.

HEDSTRÖM, Peter \& SWEDBERG, Richard (orgs.). (1998), Social mechanisms: an analytical approach to social theory. Cambridge, Cambridge University Press.

LARRETA, Enrique R. (2003), "O caminho para Casa-grande: itinerários de Gilberto Freyre", in J. C. de C. Rocha (org.), Nenhum Brasil existe, Rio de Janeiro, Editora da Uerj/Topbooks/UniverCidade.

LEITE, Dante M. (2002), O caráter nacional brasileiro. 6 ed. São Paulo, Editora da Unesp.

LITTLE, Daniel. (1991), Varieties of social explanation. Oxford, Westview Press.

LUKES, Steven. (1970), "Methodological individualism reconsidered", in D. Emmet e A. Macyntire (orgs.), Sociological theory and philosophical analysis, Londres, MacMillan.

(1973). Individualism. Oxford, Blackwell.

MELLO, Evaldo Cabral de. (2001), "O 'Ovo de Colombo" gilbertiano", in J. Falcão e R. M. B. de Araújo (orgs.), O imperador das idéias: Gilberto Freyre em questão, Rio de Janeiro, Colégio do Brasil/UniverCi- 
dade/Fundação Roberto Marinho/Topbooks.

MITCHELL, Harvey. (1996), Individual choice and the structures of history: Alexis de Tocqueville as historian reappraised. Cambridge, Cambridge University Press.

MULHALL, Terry \& MORAIS, Jorge Ventura de. (1998), “'Mapeando o Reino' da sociologia histórica: reflexões acerca do modelo teórico-metodológico de Theda Skocpol”. Bib, 45: 25-50.

OLIVEIRA, Lúcia Lippi. (2003), "Ordem e progresso em Gilberto Freyre", in E. V. Kosminsky et al. (orgs.), Gilberto Freyre em quatro tempos, São Paulo/Bauru, Unesp/Edusc.

PALHARES-BURKE, M. Lúcia G. (2001), "Um método antimetódico: Werner Heisenberg e Gilberto Freyre", in J. Falcão e R. M. B. de Araújo (orgs.), O imperador das idéias: Gilberto Freyre em questão, Rio de Janeiro, Colégio do Brasil/UniverCidade/Fundação Roberto Marinho/Topbooks.

PRIORE, Mary Del. (2003), "Sobrados e mucambos: 'a carne e a pedra' no Brasil Oitocentista”, in J. C. de C. Rocha (org.), Nenhum Brasil existe, Rio de Janeiro, Editora da Uerj/Topbooks/UniverCidade.

POPPER, Karl. (1996), O mito do contexto: em defesa da ciência e da racionalidade. Lisboa, Edições 70 .

RATTON JR., José Luiz de A. \& MORAIS, Jorge Ventura de. (2002), "O encontro de Jon Elster e Machado de Assis: racionalidade e emoções". Ciência E Trópico, 30 (2): 309-320.

. (2003), "Para ler Jon Elster: limites e possibilidades da explicação por mecanismos nas ciências sociais". Dados, 46 (2): 385-410.
REIS, José Carlos. (2002), As identidades do Brasil: de Varnhagen a FHC. 5 ed. Rio de Janeiro, Editora da FGV.

RIBEIRO, Darcy. (2001), "Gilberto Freyre: uma introdução à Casa-grande E senzala", in L\&PM. Gentidades, Porto Alegre,

RYAN, Alan. (1977), A filosofia das ciências sociais. Rio de Janeiro, Livraria Francisco Alves.

SALDANHA, Nelson. (1999), "Sobre o aspecto hermenêutico das ciências sociais: a propósito de Gilberto Freyre e de Casagrande E senzala", in F. Quintas (org.), A obra em tempos vários, Recife, Massangana.

SALLUM Jr., Brasílio. (2002), "Gilberto Freyre: Sobrados e mucambos", in L. D. Mota (org.), Introdução ao Brasil: um banquete no trópico, 2 ed., São Paulo, Senac, vol. 2.

SAMARA, Eni de M. (2003), "Relendo os 'clássicos' e interpretando o Brasil: Freyre e os estudos de família”, in E. V. Kosminsky et al. (orgs.), Gilberto Freyre em quatro tempos, São Paulo/Bauru, Editora da Unesp/Edusc.

SANTOS, Luiz A. de Castro. (1985), "A Casa-grande e o sobrado na obra de Gilberto Freyre". Anuário Antropológico, 83: 73-102.

SCHELLING, Thomas. (1978), Micromotives and macrobehavior. Nova York, Norton.

SEVCENKO, Nicolau. (2001), "Gilberto Freyre e a mídia: pioneirismo, sensibilidade e inovação", in J. Falcão e R. M. B. de Araújo (orgs.), O imperador das idéias: Gilberto Freyre em questão, Rio de Janeiro, Colégio do Brasil/UniverCidade/Fundação Roberto Marinho/Topbooks.

SIMEONI, Daniel \& DIANI, Marco. (1995), "Between objects and subjects: the nation- 
bound character of biographical research". Current Sociology, 43 (2/3): 1-10.

SKIDMORE, Thomas E. (2003), "Raízes de Gilberto Freyre", in E. V. Kosminsky et al. (orgs.), Gilberto Freyre em quatro tempos, São Paulo/Bauru, Editora da Unesp/Edusc.

SOUZA, Jessé. (2001), "A Sociologia dual de Roberto da Matta: descobrindo nossos mistérios ou sistematizando nossos auto-enganos?". Revista Brasileira de Ciências Sociais, 45: 47-67.

. (2003), "A atualidade de Gilberto Freyre", in E. V. Kosminsky et al. (orgs.), Gilberto Freyre em quatro tempos, São Paulo/Bauru, Editora da Unesp/Edusc.

STRIEDER, Inácio. (1999), “A compreensão do homem no pensamento de Gilberto Freyre", in F. Quintas (org.), A obra em tempos vários, Recife, Massangana.

VEYNE, Paul. (1995), Como se escreve a história. Trad. Alda Baltar e M. Auxiliadora Kneipp. 3 ed. Brasília, Editora da UnB.

VELOSO, Mariza \& MADEIRA, Angélica. (2000), Leituras brasileiras: itinerários no pensamento social e na literatura. 2 ed. São Paulo, Paz e Terra.

VIANNA, Hermano. (2000), “'A Rivalidade entre o homem moço e o homem velho': o conflito de gerações em Sobrados e mucambos", in M. do C. T. de Miranda (org.), Que somos nós? 60 anos de Sobrados e mucambos, Recife, Massangana.

VILANOVA, Lourival. (1999), "Gilberto Freyre aspectos de sua obra: a sociologia como ciência cultural", in F. Quintas (org.), A obra em tempos vários, Recife, Massangana.

VILA NOVA, Sebastião. (1995a), "Cultura e sociedade em Gilberto Freyre", in M. C. de
Andrade (org.), Gilberto Freyre: pensamento e ação, Recife, Massangana.

(1995b), "Gilberto Freyre: do pragmatismo à 'Escola de Chicago'". Estudos de Sociologia (Recife), 1 (1): 23-34.

(1995c). Sociologias e pós-sociologia em Gilberto Freyre: algumas fontes e afinidades teóricas e metodológicas do seu pensamento. Recife Massangana.

(1999), "Pragmatismo, história e indivíduo em Casa-grande E senzala", in $\mathrm{F}$. Quintas (org.), A obra em tempos vários, Recife, Massangana.

VILLAS BOAS, Gláucia. (2003), "Casa grande e Terra grande, sertões e senzala: a sedução das origens", in E. V. Kosminsky et al. (orgs.), Gilberto Freyre em quatro tempos, São Paulo/Bauru, Editora da Unesp/Edusc. 


\section{GILBERTO FREYRE E A ARTI- CULAÇÃO DOS NÍVEIS MICRO E MACRO NA SOCIOLOGIA \\ GILBERTO FREYRE AND THE ARTICULATION OF MICRO AND MACRO LEVELS IN SO- CIOLOGY}

\author{
Jorge Ventura de Morais e \\ José Luiz Ratton Jr.
}

\section{Palavras-chave}

Gilberto Freyre; Sociologia e

biografia; Explicação; Redução

e agregação; Articulação micromacro.

Este artigo aborda a obra de Gilberto Freyre a partir de um dos problemas centrais da teoria sociológica contemporânea: a articulação entre os níveis micro e macro. Dirigimos o foco da análise para a relação entre fenômenos macrossociais (formação da família, decadência do patriarcado rural, ascensão do bacharel e formação de uma cultura urbana nacional) e as biografias - nível micro utilizadas com freqüência pelo autor (Félix Cavalcanti de Albuquerque, Padre Ibiapina, Joaquim Nabuco e Gonçalves Dias, entre outros). Procuramos avaliar se a passagem do nível macro para o nível micro, na obra do autor pernambucano, pode ser entendida a partir de categorias como redução, agregação e superveniência.
Jorge Ventura de Morais and José Luiz Ratton Jr.

\section{Keywords}

Gilberto Freyre; Sociology and biography; Explanation; Reduction and aggregation; Micro-macro articulation

This paper discusses Gilberto Freire's work from one of the core problems of the sociological contemporary theory: the micro-macro link. We have focused the analysis toward the relation amongst macrosocial phenomena (family formation, failure of the rural patriarchy, rise of the law graduates (bacharéis) and the formation of a national urban culture) and the biographies - micro level - frequently used in Freyre's writings (Félix Cavalcanti de Albuquerque, Priest Ibiapina, Joaquim Nabuco e Gonçalves Dias, among others). Hence, we have sought to evaluate whether the passage from the macro toward the micro level, in the work of the mentioned author, can be understood from categories such as reduction, aggregation, and supervenience.

\section{GILBERTO FREYRE ET L'AR- TICULATION DES NIVEAUX MICRO ET MACRO EN SOCIOLOGIE}

Jorge Ventura de Morais et José Luiz Ratton Jr.

\section{Mots-clés}

Gilberto Freyre; Sociologie et biographie; Explication; Réduction et agrégation; Articulation micro-macro.

L'article aborde l'œuvre de Gilberto Freyre à partir d'un des problèmes centraux de la théorie sociologique contemporaine: celui de l'articulation entre les niveaux micro et macro en sociologie. Notre analyse porte sur le rapport entre certains phénomènes macro-sociaux (formation de la famille, décadence du patriarcat rural, montée des juristes et formation d'une culture urbaine nationale) et les biographies fréquemment utilisées par l'auteur (parmi lesquelles, celles de Félix Cavalcanti de Albuquerque, père Ibiapina, Joaquim $\mathrm{Na}$ buco et Gonçalves Dias). Nous cherchons, ainsi, à identifier si le passage de l'échelle macro à l'échelle micro dans l'analyse de l'auteur en question peut être saisie à partir de catégories telles que la réduction, l'agrégation et la survenance. 